\title{
ACÚMULO DE MASSA SECA E MACRONUTRIENTES PELO SORGO SACARINO EM DIFERENTES NÍVEIS DE ADUBAÇÃO NPK
}

\author{
FLÁVIA CRISTINA DOS SANTOS ${ }^{1}$, LEANDRO FLÁVIO CARNEIRO², \\ MANOEL RICARDO DE ALBUQUERQUE FILHO' ${ }^{1}$, MÔNICA MATOSO CAMPANHA ${ }^{1}$, \\ MARIA LÚCIA FERREIRA SIMEONE ${ }^{1}$ e GUILHERME MOURA FERREIRA JÚLIO²
}

\author{
${ }^{1}$ Embrapa Milho e Sorgo, Sete Lagoas, MG, Brasil, \\ flavia.santos@embrapa.br,manoel.ricardo@embrapa.br,monica.matoso@embrapa.br,marialucia.simeone@embrapa.br \\ ${ }^{2}$ Universidade Federal de São João del-Rei, SeteLagoas, MG, Brasil,leandrocarneiro@ufpr.br, guilhermemoura15@hotmail.com
}

Revista Brasileira de Milho e Sorgo, v.18, n.1, p. 1-13, 2019

\begin{abstract}
RESUMO - Com o objetivo de determinar o acúmulo de massa seca e macronutrientes ao longo do ciclo do sorgo sacarino BRS 506, em diferentes níveis de adubação NPK, foram instalados experimentos por dois anos, em Latossolo, sob irrigação. Utilizou-se o delineamento experimental de blocos ao acaso, com quatro repetições. Os tratamentos foram de quatro níveis tecnológicos, relacionados à adubação $\mathrm{N}_{-} \mathrm{P}_{2} \mathrm{O}_{5-} \mathrm{K}_{2} \mathrm{O}$, em kg ha-1: muito baixo (NPK = 0-0-0); baixo (NPK = 80-50-80); médio (NPK = 160-100-160) e alto (NPK = 240-150-240). Avaliaram-se o acúmulo de massa seca e macronutrientes aos 30, 50, 70, 90 e 110 dias após plantio (DAP). No geral, foram ajustados modelos polinomiais de segundo grau. $\mathrm{O}$ acúmulo de massa seca e macronutrientes apresentou taxa inicial baixa, até cerca de $30 \mathrm{DAP}$, e a partir daí aumentou consideravelmente, até próximo à maturação, para então se estabilizar e decrescer. No geral, o acúmulo de massa seca foi maior no nível tecnológico alto e o acúmulo de nutrientes não diferiu entre os níveis médio e alto, sendo menor para os níveis baixo e muito baixo. Recomendam-se 160-100-160 kg ha-1 de N- $\mathrm{P}_{2} \mathrm{O}_{5}$ $\mathrm{K}_{2} \mathrm{O}$ para produtividade satisfatória do sorgo sacarino e manutenção da fertilidade do solo, além de outras práticas que favoreçam a ciclagem de nutrientes.
\end{abstract}

Palavras-chave: Sorghum bicolor (L.) Moench, nutrição, fertilização, absorção de nutrientes.

\section{DRY MASS AND MACRONUTRIENTS ACCUMULATION OF SWEET SORGHUM IN DIFFERENT LEVELS OF NPK FERTILIZATION}

\begin{abstract}
In order to determine the dry mass and macronutrients accumulation along the sweet sorghum BRS 506 cycle, at different levels of NPK fertilization, experiments were carried out for two years in Oxisol, under irrigation. The experimental design was a randomized complete block with four replicates. The treatments comprised four levels of soil fertility, related to $\mathrm{N}-\mathrm{P}_{2} \mathrm{O}_{5} \mathrm{~K}_{2} \mathrm{O}$ fertilization, in $\mathrm{kg} \mathrm{ha}^{-1}$ : very low ( $\left.\mathrm{NPK}=0-0-0\right)$; low (NPK = 80-50-80); medium (NPK $=160-100-160)$ and high $(\mathrm{NPK}=240-150-240)$. Dry matter accumulation and macronutrients were evaluated at 30, 50, 70, 90 and 110 days after planting (DAP). In general, polynomial models of the second degree were adjusted. Dry matter and macronutrient accumulation presented a low initial rate, until $30 \mathrm{DAP}$, from there it increased considerably until near the maturation, then stabilizing and decreasing. In general, dry mass accumulation was higher at high technological level and nutrient accumulation did not differ between medium and high levels, being lower for low and very low levels. It is recommended to apply $160-100-160 \mathrm{~kg} \mathrm{ha}^{-1}$ of N-P $\mathrm{O}_{5}-\mathrm{K}_{2} \mathrm{O}$ for a satisfactory productivity of sorghum and maintenance of soil fertility, in addition to other practices favoring the nutrients cycling.
\end{abstract}

Keywords: Sorghum bicolor (L.) Moench, nutrition, fertilization, nutrient uptake. 
Fontes renováveis de energia estão entre as demandas mais prementes da sociedade moderna. No Brasil, a geração de energia com o uso de produtos agrícolas (agroenergia) já representa a segunda principal fonte de energia primária no Brasil (Brasil, 2018), sendo a produção de etanol por espécies vegetais, como a cana-de-açúcar, uma alternativa menos poluente e economicamente mais viável para substituir o consumo dos combustíveis fósseis.

Nesse sentido, o sorgo sacarino (Sorghum bicolor (L.) Moench) tem sido apontado como promissor para produção de etanol em países como Brasil, Estados Unidos, China e Índia (Han et al., 2011; Fernandes et al., 2014). As características como alta capacidade de produção de biomassa e armazenamento de açúcares no colmo, semelhantes às da cana-de-açúcar, indicam que o sorgo sacarino apresenta excelente potencial para produção deste combustível (Soares et al., 2014; Ameen et al., 2017). Além do seu potencial para atender à crescente demanda energética, esta cultura também pode ser aproveitada na indústria para produção de açúcar (Regassa \&Wortmann, 2014).

O sorgo é uma gramínea tropical originária da África e está adaptada a diferentes condições ambientais, e sua principal qualidade é o bom desempenho produtivo sob restrição hídrica, em comparação com outras culturas, como o milho, por exemplo (Wortmann et al., 2010; Hao et al., 2014; Maw et al., 2016). Entretanto, a cultura responde favoravelmente ao fornecimento de água, bem como de nutrientes, principalmente quando se busca alto índice de produtividade (Hao et al., 2014; Santos et al., 2015; Borges et al., 2016). Amouzou et al. (2018) verificaram que mesmo em condições de clima seco, o sorgo respondeu positivamente ao aporte de nutrientes, absorvendo mais que o dobro de $\mathrm{N}$ e $\mathrm{P}$, e produzindo entre 45 e $60 \%$ a mais de biomassa em solos adubados em comparação com a produção em solos não corrigidos. Incremento na produção de biomassa aérea de sorgo com o aumento da adubação também foi encontrado por outros autores (Maw et al., 2016; Ameen et al., 2017).

As necessidades nutricionais do sorgo são determinadas pela quantidade de nutrientes absorvidos, entretanto, a demanda de nutrientes pelo sorgo sacarino ainda é pouco estudada e a maioria da literatura faz referência ao sorgo granífero e forrageiro que se origina de regiões temperadas. Portanto, o conhecimento sobre a absorção de nutrientes ao longo do tempo, a capacidade de utilização destes elementos e o rendimento das plantas de sorgo sacarino, frente às diferentes taxas de aplicação de fertilizantes, constitui-se em importante ferramenta na busca da eficiência no uso de fertilizantes, principalmente em condições de alta no preço dos insumos. Ao otimizar a aplicação de nitrogênio $(\mathrm{N})$, fósforo (P) e potássio $(\mathrm{K})$ nos sistemas produtivos, para um alto rendimento de biomassa, pode-se reduzir os custos da fertilização destes macronutrientes mais importantes, o que afeta o rendimento da cultura, e torna a produção de sorgo sacarino mais sustentável (Han et al., 2011; Maw et al., 2016; Ameen et al., 2017). Além disso, o excesso de fertilizantes no solo pode contaminar águas subterrâneas, pelo processo de lixiviação, e o aumento da emissão de gases de efeito estufa (Hao et al., 2014).

Assim, a avaliação da marcha de absorção de nutrientes para o sorgo sacarino, em função da idade das plantas, servirá para subsidiar a definição da melhor época e quantidade de aplicação dos fertilizantes para o alcance de altas produtividades, contribuindo para a utilização racional dos insumos. Além disso, permitirá estimar a quantidade de nutrientes exportada pela colheita possibilitando adequar estratégias 
de reposição ao solo, evitando seu empobrecimento químico.

Neste contexto, o objetivo do trabalho foi determinar o acúmulo de massa seca e macronutrientes ao longo do ciclo do sorgo sacarino, em diferentes níveis de adubação NPK.

\section{Material e Métodos}

Foram conduzidos, nos anos de 2012 e 2013, experimentos no Campo Experimental da Embrapa Milho e Sorgo, em Sete Lagoas, MG, sob irrigação por aspersão, com base no aplicativo computacional Irrigafácil 2.0 (Albuquerque et al., 2013).

Os experimentos foram instalados em Latossolo Vermelho distroférrico típico, com as seguintes características químicas e físicas antes da implantação dos ensaios: $\mathrm{pH}$ em água $=5,8 ; \mathrm{Al}=0,25 ; \mathrm{Ca}=3,5$; $\mathrm{Mg}=0,6 ; \mathrm{T}=8,7\left(\mathrm{cmol}_{\mathrm{c}} \mathrm{dm}^{-3}\right) ;$ P-Mehlich $1=8,0$; $\mathrm{K}=82,0\left(\mathrm{mg} \mathrm{dm}^{-3}\right) ; \mathrm{V}=50(\%)$; teor de argila e matéria orgânica $=65,0$ e 3,1 $\left(\right.$ dag kg $\left.^{-1}\right)$. O solo recebeu 1,0 t ha-1 de calcário dolomítico (PRNT $95 \%$ ), no dia 17/01/2012, a fim de elevar a saturação por bases a $60 \%$.

A altitude local é de $755 \mathrm{~m}$. O clima da região, segundo Köppen, é classificado como Aw, tropical com estação seca, e as condições climáticas da área durante o ciclo de crescimento do sorgo se encontram na Figura 1 (Coordenadas da estação meteorológica: latitude $-19^{\circ} 29^{\prime} 05^{\prime}$, longitude $-44^{\circ} 10^{\prime} 26^{\prime \prime}$ ).

$\mathrm{O}$ delineamento experimental utilizado foi o de blocos ao acaso, com quatro repetições. Os tratamentos consistiram de quatro níveis tecnológicos, relacionados à adubação NPK, sendo nível muito baixo $\left(\mathrm{NPK}=0-0-0 \mathrm{~kg} \mathrm{ha}^{-1}\right)$, ou seja, a testemunha sem aplicação dos insumos; nível baixo (NPK = 80-50-80 $\mathrm{kg} \mathrm{ha}^{-1}$ ); médio (NPK = 160-100-160 $\mathrm{kg} \mathrm{ha}^{-1}$ ) e nível alto $\left(\mathrm{NPK}=240-150-240 \mathrm{~kg} \mathrm{ha}^{-1}\right)$.
As parcelas foram constituídas por seis linhas de cinco metros de comprimento e espaçadas de 0,7 m. A parcela útil foi composta pelas quatro linhas centrais de quatro metros de comprimento, eliminando-se $0,5 \mathrm{~m}$ de bordadura em cada extremidade.

Utilizou-se a cultivar de sorgo sacarino BRS 506 com estande de 120.000 plantas por hectare. No primeiro cultivo, o plantio foi realizado em 09/02/12, e no segundo em 05/02/13. A adubação de plantio foi realizada no sulco de semeadura e composta pelas doses totais de P de cada nível avaliado, mais 30 e $60 \mathrm{~kg} \mathrm{ha}^{-1}$ de $\mathrm{N}$ e $\mathrm{K}_{2} \mathrm{O}$, respectivamente, à exceção da testemunha absoluta. Aplicou-se também a dose de $100 \mathrm{~kg} \mathrm{ha}^{-1}$ de FTE BR12 em todas as parcelas.
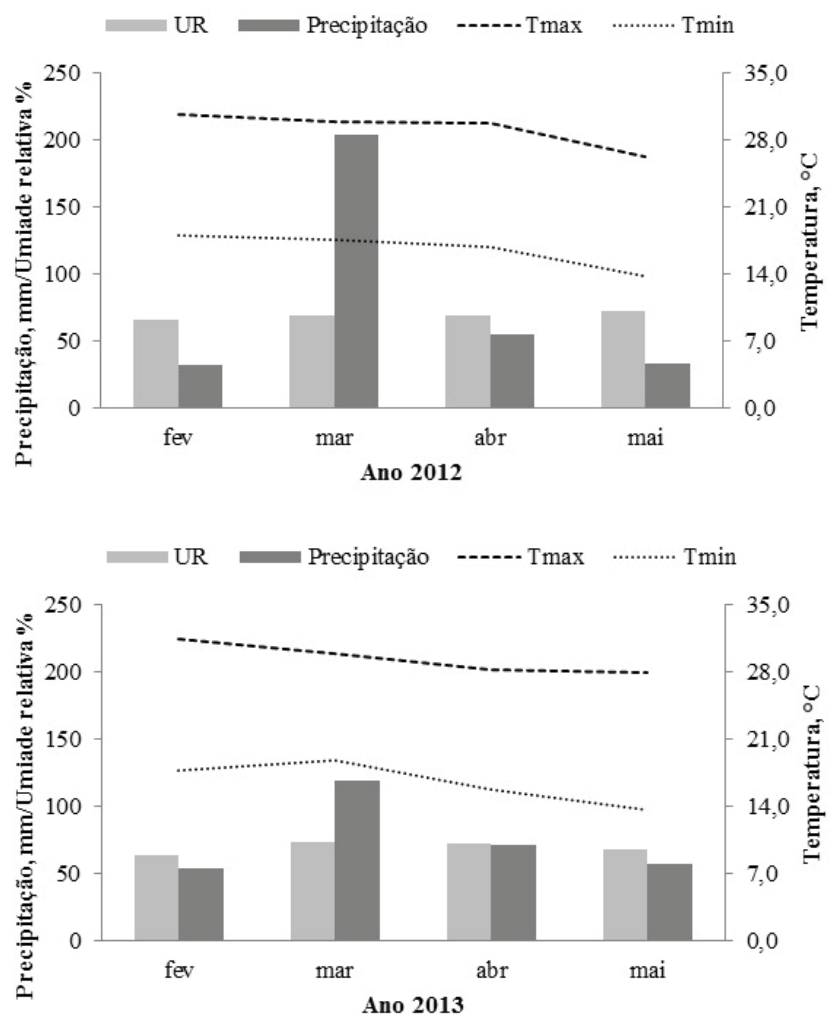

Figura 1. Condições climáticas durante o ciclo de crescimento do sorgo. Sete Lagoas-MG. Ano 2012 primeiro ano de cultivo e Ano 2013 - segundo ano de cultivo. 
As doses complementares de $\mathrm{N}$ e $\mathrm{K}$ relacionadas a cada nível tecnológico foram aplicadas em cobertura, aos 30 dias após o plantio, quando as plantas apresentavam 4 a 6 folhas completamente desenvolvidas. Os fertilizantes foram aplicados superficialmente e ao lado, à distância de $20 \mathrm{~cm}$, das linhas de plantio. As fontes de insumos utilizadas nas adubações de plantio e cobertura foram superfosfato triplo, ureia e cloreto de potássio. A colheita foi realizada em 31/05/12 e em 27/05/13, nos dois anos do experimento.

Foram avaliados o acúmulo de massa seca e macronutrientes (N, P, K, Ca, Mg e S) aos 30, 50, 70, 90 e 110 dias após o plantio (DAP).

Foram ajustadas equações de regressão para os efeitos simples e significativos. Para a escolha dos modelos de regressão baseou-se nos critérios de análise de variância da regressão $(\mathrm{p}<0,05)$, na significância dos parâmetros, no coeficiente de determinação $\left(\mathrm{R}^{2}\right)$ e no significado biológico do fenômeno. O programa estatístico utilizado foi o Sisvar (Ferreira, 2011). Foi realizado o teste de médias por Tukey ao nível de $5 \%$ de probabilidade para comparar os níveis tecnológicos para os acúmulos de massa seca e nutrientes aos 90 DAP.

\section{Resultados e Discussão}

\section{Acúmulo de massa seca}

As condições climáticas foram semelhantes nos dois anos do experimento com sorgo, havendo apenas uma melhor distribuição de chuvas no segundo ano (2013) (Figura 1), que resultou em maior estabilidade de acúmulo de massa seca entre os diferentes níveis tecnológicos (Tabelas 1 e 2).

Os acúmulos de massa seca e nutrientes pelo sorgo sacarino no primeiro ano encontram-se na Figura $2 \mathrm{~A}$ a $\mathrm{G}$. Os modelos polinomiais ajustados eviden- ciam menores acúmulos das variáveis avaliadas no nível tecnológico muito baixo, ou seja, sem aplicação dos fertilizantes, em relação aos outros níveis, em que houve a adubação das plantas. Esse comportamento era esperado, pois em condição de baixa disponibilidade de nutrientes o crescimento da planta é comprometido. Além disso, os modelos ajustados para acúmulo de massa seca e nutrientes foram o linear para o nível tecnológico de fertilidade muito baixo, mostrando que a planta tem potencial maior de crescimento e de acúmulo de nutrientes, pois não atingiu o ápice; enquanto para os demais níveis os modelos ajustados foram os quadráticos (exceção para o modelo linear de acúmulo de massa seca do nível alto de fertilidade, Figura 2 A). No início há um acúmulo lento de massa seca da planta e nutrientes, que se acentua próximo ao emborrachamento das plantas até o enchimento dos grãos, reduzindo após este período, quando com a maturação fisiológica ocorrem as perdas de folhas e redução da absorção de nutrientes do solo, sendo estes translocados de outras partes da planta para o principal dreno, que são os grãos.

Pelos modelos ajustados, o acúmulo máximo de massa seca da planta se daria aos 180 DAP (23 t $\mathrm{ha}^{-1}$ de massa seca) para o nível tecnológico baixo e 135 DAP (20 t ha ${ }^{-1}$ de massa seca) para o nível tecnológico médio, valores acima do máximo avaliado neste trabalho, que foi de 110 DAP (Figura 2 A). Já para o nível muito baixo e alto, como o ajuste foi linear, o acúmulo máximo pode ser considerado o último de avaliação, ou seja, aos 110 DAP (7 e 19 t ha $^{-1}$ de massa seca, respectivamente) (Figura 2 A).

No segundo ano (Figura $3 \mathrm{~A}$ ), a diferença para os tratamentos com e sem adubação NPK foi menor, e a produtividade do nível tecnológico muito baixo (sem adubação) foi maior que no primeiro ano, e houve ajustes de modelos quadráticos em todas as situa- 


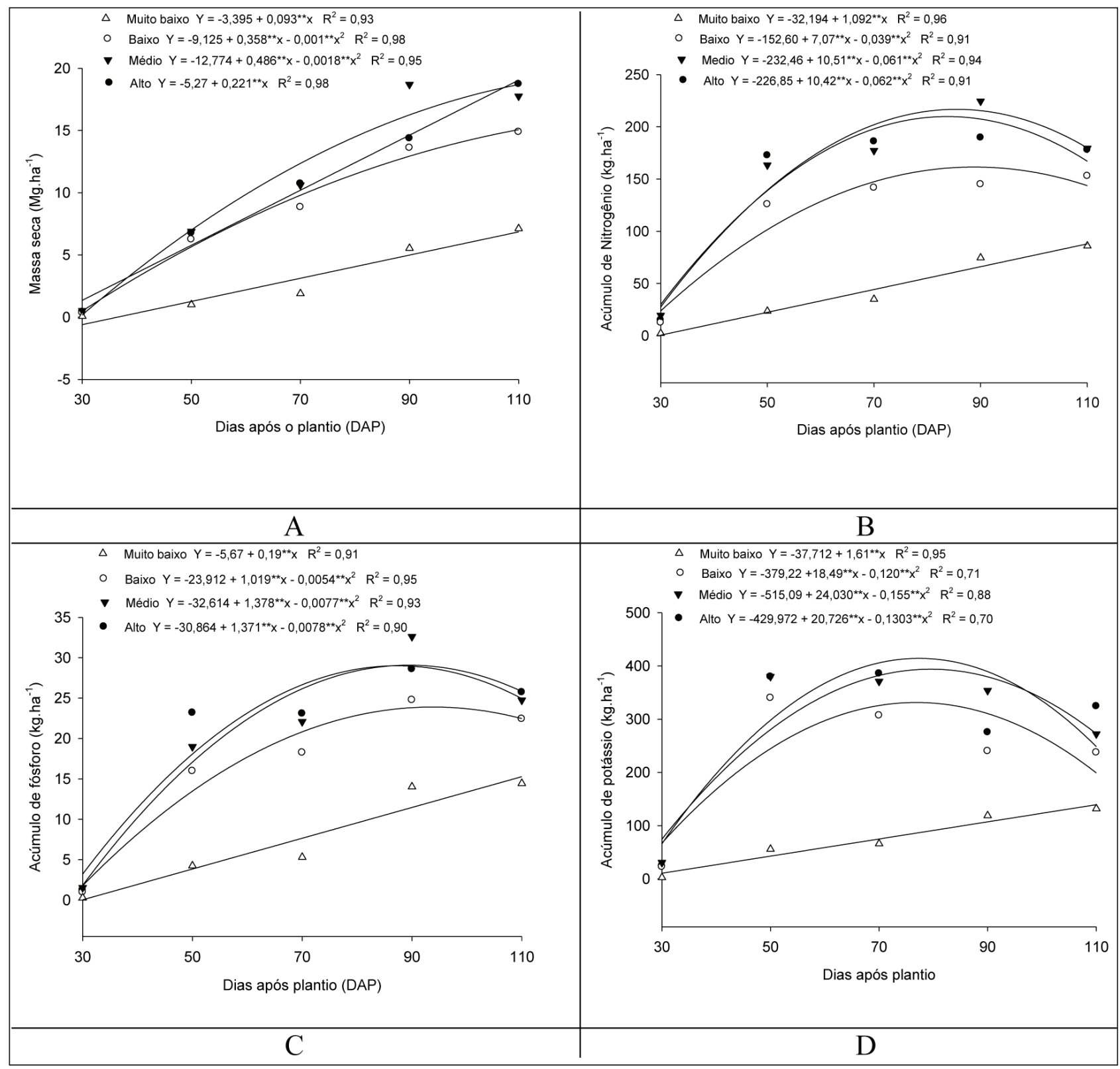

Figura 2. Acúmulo de massa seca, nitrogênio, fósforo e potássio em função dos níveis tecnológicos e dias após o plantio (DAP) da cultura do sorgo sacarino, cultivado no município de Sete Lagoas. Primeiro ano de cultivo. 


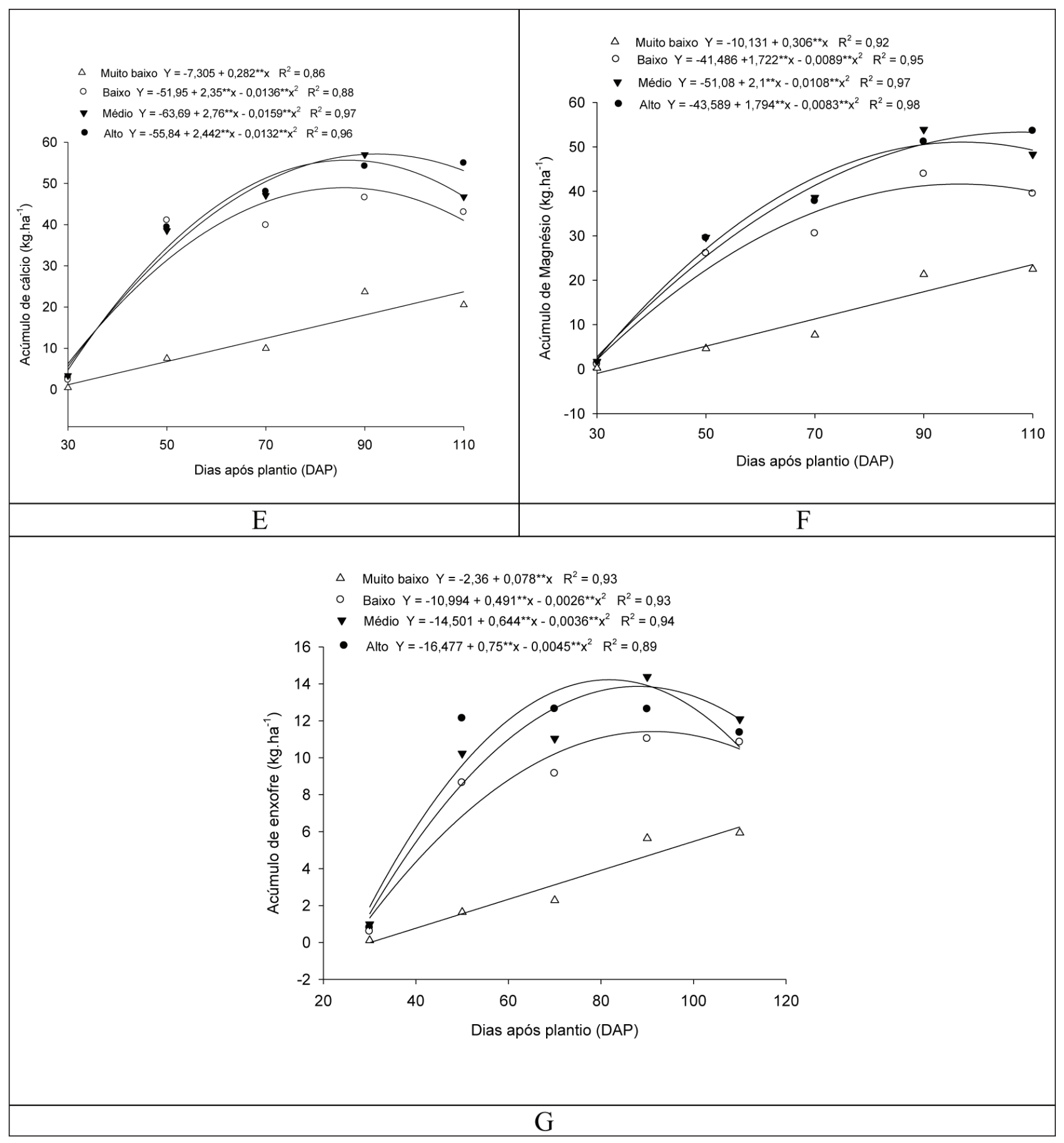

Figura 2. Continuação.... Acúmulo de cálcio, magnésio e enxofre em função dos níveis tecnológicos e dias após o plantio (DAP) da cultura do sorgo sacarino, cultivado no município de Sete Lagoas. Primeiro ano de cultivo. 
ções. Pelos dados do trabalho, o máximo acúmulo de massa seca se deu aos 90 DAP, entretanto, pelos modelos ajustados isso ocorreu entre 101 (nível médio, $17 \mathrm{t} \mathrm{ha}^{-1}$ de massa seca) e 148 DAP (nível baixo, 17 t ha ${ }^{-1}$ de massa seca), considerando os diferentes níveis tecnológicos e sem uma relação direta entre eles e DAP para acúmulo máximo de massa seca.

A quantidade de massa seca acumulada no início do desenvolvimento das plantas, até cerca de 30 DAP, é muito baixa, e a partir daí se inicia taxa de acúmulo muito intensa, com taxa máxima de acúmulo diário (TMAD) de massa seca de $327 \mathrm{~kg} \mathrm{ha}^{-1}$ para o nível baixo de fertilidade do solo e de $430 \mathrm{~kg} \mathrm{ha}^{-1}$ para o nível médio de fertilidade. Esses valores são próximos ao valor de $352 \mathrm{~kg} \mathrm{ha}^{-1}$ de TMAD do híbrido de sorgo forrageiro BRS 610 obtido por Franco (2011). Este autor observou que no início do desenvolvimento do sorgo forrageiro, o acúmulo de massa seca é pouco expressivo, se intensificando a partir dos 31 dias após a emergência (DAE) e se estendendo até os 80 DAE, chegando ao final do ciclo com um ritmo de crescimento bastante reduzido em relação ao anterior. Essa tendência também foi observada por Ribeiro (2010) com o sorgo forrageiro BRS 610 cultivado na safrinha.

Formiga et al. (2012) em estudo com marcha de absorção de NPK em sorgo granífero sacarino também relatam o mesmo padrão de acúmulo de massa seca, com crescimento inicial lento, aumento significativo do crescimento da planta a partir dos 63 DAP e crescimento constante até os 103 DAP.

Esse comportamento mostrado nestes trabalhos é confirmado por Fornasiere Filho e Fornasiere (2009), que afirmam que o acúmulo de massa seca pela cultura do sorgo apresenta uma fase inicial lenta, até ao estádio de 7 folhas completamente desenvolvidas, o que compreende cerca de 25-30 DAE, e este envolve essencialmente o crescimento das folhas. A partir daí, há um intenso acúmulo de massa seca, representado principalmente pelo crescimento do colmo, da panícula e de grãos, com destaque para a fase reprodutiva e o enchimento de grãos.

Considerando os níveis tecnológicos e 90 DAP (época predominante de maior acúmulo de massa seca e nutrientes dos dados obtidos neste trabalho), no primeiro ano, o nível muito baixo foi o que resultou em menor acúmulo de massa seca das plantas de sorgo sacarino, seguido dos baixo e médio, que não diferiram entre si, sendo o nível tecnológico alto, com aplicação de 240-150-240 de NPK, o que resultou em maior acúmulo de massa seca do sorgo sacarino (Tabela 1). Como se sabe, os nutrientes N, P e K apresentam relação direta com o aumento de produtividade das culturas, e, assim, a fertilização proporciona maior produção das culturas.

No segundo ano, o acúmulo de massa seca do nível tecnológico muito baixo não diferiu estatisticamente do nível baixo e alto, havendo apenas destaque para o nível médio, que se diferiu dos demais (Tabela 2). Esse comportamento pode ser explicado por algum efeito residual da adubação NPK do ano anterior, pois as parcelas e os tratamentos do segundo ano do experimento foram os mesmos do primeiro ano, além de um melhor efeito da calagem, pois no primeiro ano o plantio foi realizado a menos de um mês da aplicação do calcário.

\section{Acúmulo de macronutrientes}

Nos dois anos avaliados, o acúmulo de macronutrientes pelo sorgo sacarino seguiu comportamento semelhante ao acúmulo de massa seca (Figuras 2 e 3), como era esperado pela relação direta existente entre essas duas variáveis.O sorgo apresenta períodos diferentes de intensa absorção, com o primeiro ocorrendo 


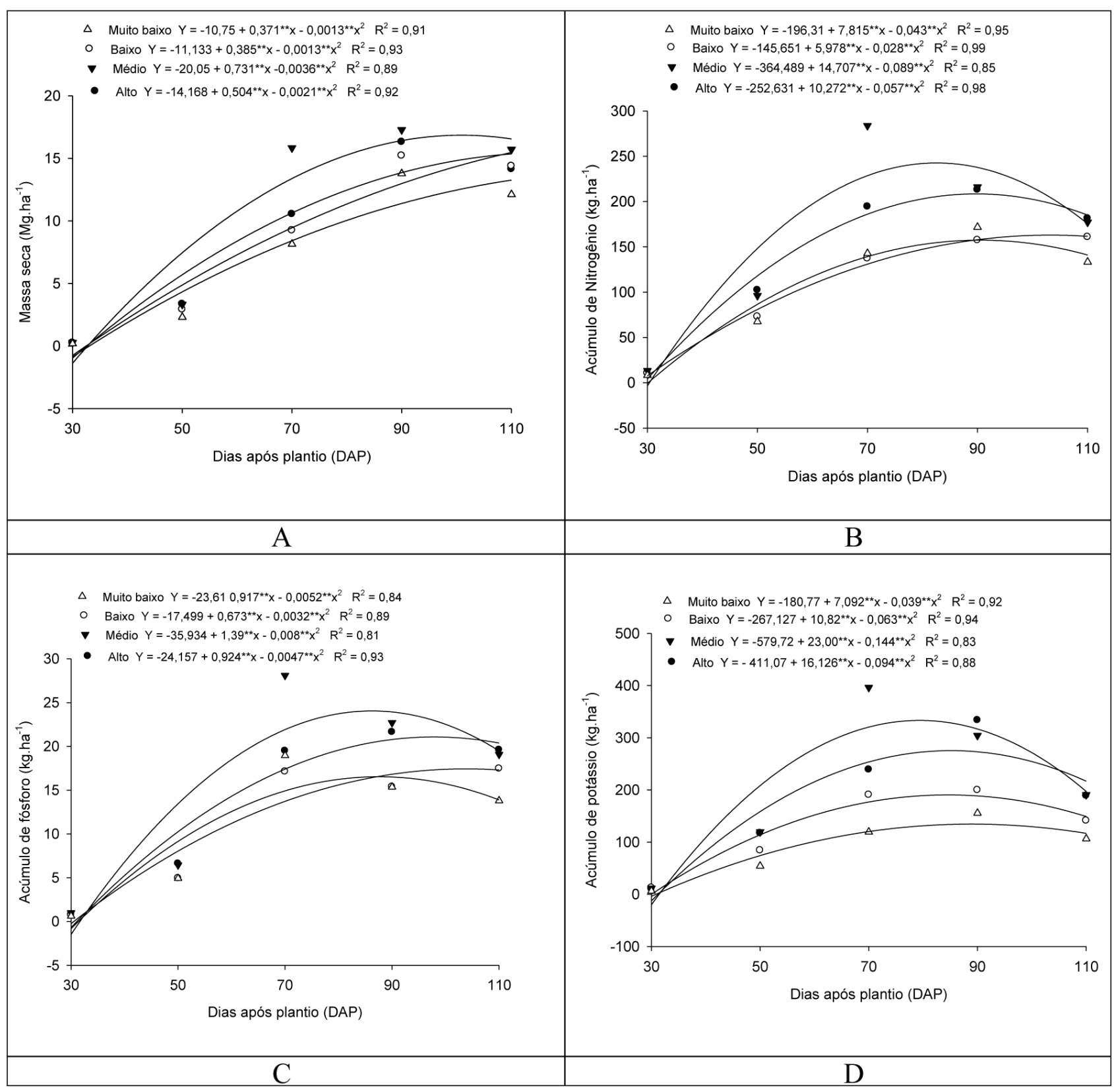

Figura 3. Acúmulo de massa seca, nitrogênio, fósforo e potássio em função dos níveis tecnológicos e dias após o plantio (DAP) da cultura do sorgo sacarino, cultivado no município de Sete Lagoas. Segundo ano de cultivo. 


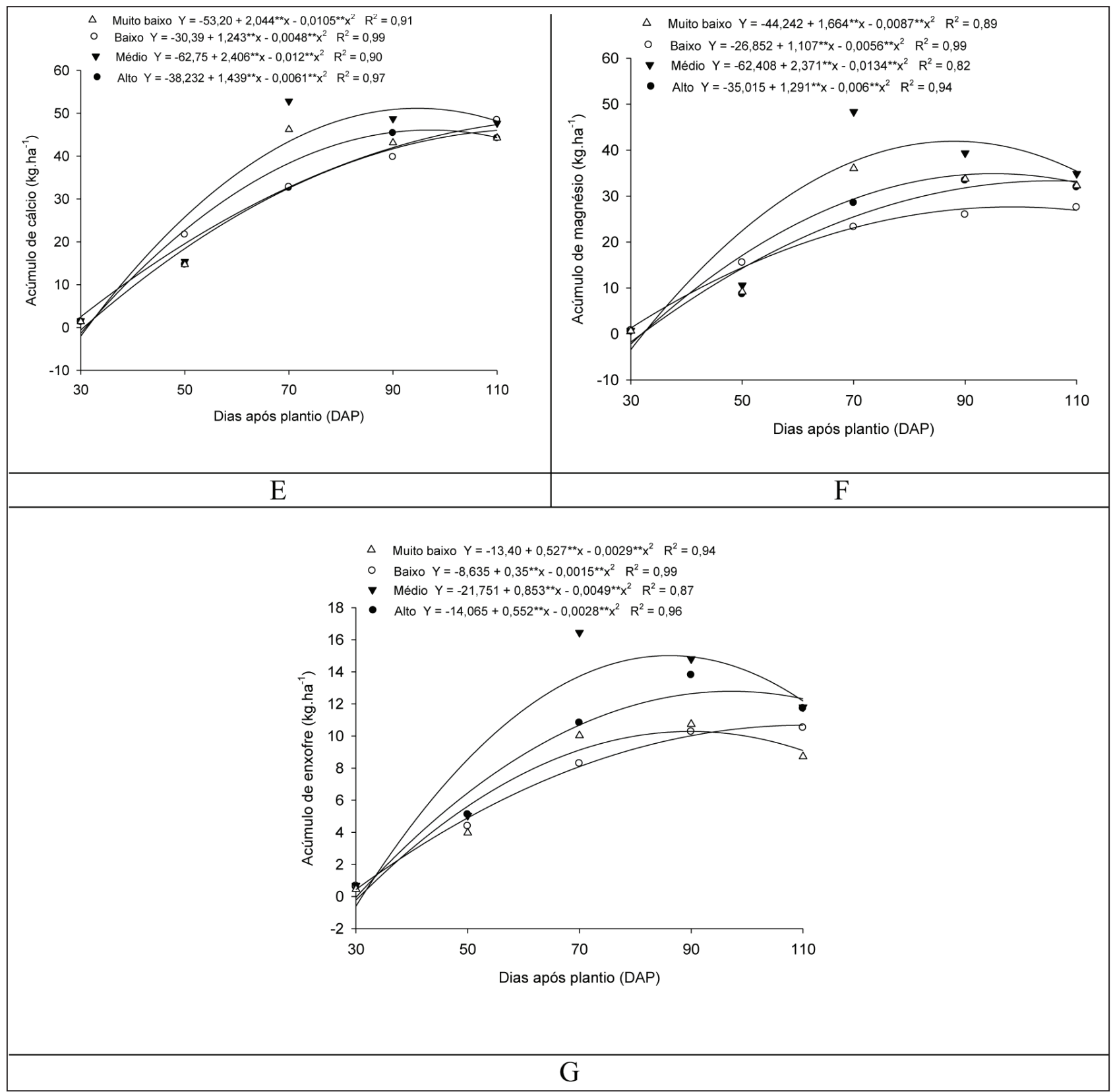

Figura 3. Continuação.... Acúmulo de cálcio, magnésio e enxofre em função dos níveis tecnológicos e dias após o plantio (DAP) da cultura do sorgo sacarino, cultivado no município de Sete Lagoas. Segundo ano de cultivo. 
Tabela 1. Massa seca, acúmulo de nitrogênio $(\mathrm{N})$, fósforo $(\mathrm{P})$, potássio $(\mathrm{K})$, cálcio $(\mathrm{Ca})$, magnésio $(\mathrm{Mg})$ e enxofre (S) na cultura do sorgo sacarino cultivado sob níveis tecnológicos aos 90 DAP, em Sete Lagoas-MG. Primeiro ano de cultivo.

\begin{tabular}{|c|c|c|c|c|c|c|c|}
\hline \multirow{2}{*}{$\begin{array}{c}\text { Nível } \\
\text { tecnológico }\end{array}$} & Massa seca & $\mathbf{N}$ & $\mathbf{P}$ & $\mathbf{K}$ & $\mathrm{Ca}$ & Mg & $\mathbf{S}$ \\
\hline & Mg ha $^{-1}$ & \multicolumn{6}{|c|}{$\mathrm{kg} \mathrm{ha}^{-1} \ldots$} \\
\hline Muito baixo & $5,54 \mathrm{C}$ & $74,6 \mathrm{C}$ & $14,0 \mathrm{C}$ & $118,8 \mathrm{C}$ & $23,7 \mathrm{~B}$ & $21,3 \mathrm{~B}$ & $5,6 \mathrm{C}$ \\
\hline Baixo & $13,61 \mathrm{~B}$ & $144,9 \mathrm{~B}$ & $24,7 \mathrm{~B}$ & $240,0 \mathrm{~B}$ & $46,5 \mathrm{~A}$ & $43,9 \mathrm{~A}$ & $11,0 \mathrm{~B}$ \\
\hline Médio & $14,37 \mathrm{~B}$ & $224,5 \mathrm{~A}$ & $32,6 \mathrm{~A}$ & $353,8 \mathrm{~A}$ & $56,9 \mathrm{~A}$ & $53,9 \mathrm{~A}$ & $14,3 \mathrm{~A}$ \\
\hline Alto & $18,70 \mathrm{~A}$ & $189,6 \mathrm{~A}$ & $28,6 \mathrm{AB}$ & $275,4 \mathrm{AB}$ & $54,1 \mathrm{~A}$ & $51,1 \mathrm{~A}$ & $12,6 \mathrm{AB}$ \\
\hline C.V. (\%) & 16,6 & 16,4 & 20,6 & 22,1 & 24,7 & 26,2 & 17,2 \\
\hline
\end{tabular}

Médias seguidas da mesma letra maiúscula na coluna não diferem entre si ao nível de $5 \%$ de probabilidades pelo teste de Tukey.

Tabela 2. Massa seca, acúmulo de nitrogênio $(\mathrm{N})$, fósforo $(\mathrm{P})$, potássio $(\mathrm{K})$, cálcio $(\mathrm{Ca})$, magnésio $(\mathrm{Mg})$ e enxofre (S) na cultura do sorgo sacarino cultivado sob níveis tecnológicos aos 90 DAP, em Sete Lagoas-MG. Segundo ano de cultivo.

\begin{tabular}{|c|c|c|c|c|c|c|c|}
\hline \multirow{2}{*}{$\begin{array}{c}\text { Nível } \\
\text { tecnológico }\end{array}$} & Massa seca & $\mathbf{N}$ & $\mathbf{P}$ & $\mathbf{K}$ & Ca & Mg & $\mathbf{S}$ \\
\hline & $\mathrm{Mg} \mathrm{ha}^{-1}$ & \multicolumn{6}{|c|}{$\ldots \ldots \ldots . . \mathrm{kg} \mathrm{ha}^{-1} \ldots \ldots$} \\
\hline Muito baixo & $13,78 \mathrm{~B}$ & $171,7 \mathrm{AB}$ & $15,3 \mathrm{~B}$ & $155,5 \mathrm{C}$ & $43,1 \mathrm{~A}$ & $33,7 \mathrm{AB}$ & $10,7 \mathrm{C}$ \\
\hline Baixo & $15,21 \mathrm{AB}$ & 157,4 B & $15,3 \mathrm{~B}$ & $199,8 \mathrm{BC}$ & $39,7 \mathrm{~A}$ & $25,9 \mathrm{~B}$ & $10,2 \mathrm{C}$ \\
\hline Médio & $17,28 \mathrm{~A}$ & $216,1 \mathrm{~A}$ & $22,7 \mathrm{~A}$ & $304,3 \mathrm{AB}$ & $48,7 \mathrm{~A}$ & $39,3 \mathrm{~A}$ & $14,8 \mathrm{~A}$ \\
\hline Alto & $16,31 \mathrm{AB}$ & $213,0 \mathrm{~A}$ & $21,6 \mathrm{~A}$ & $333,7 \mathrm{~A}$ & $45,3 \mathrm{~A}$ & $33,4 \mathrm{AB}$ & $13,8 \mathrm{AB}$ \\
\hline C.V. (\%) & 19,9 & 19,7 & 25,0 & 38,0 & 21,9 & 26,0 & 22,4 \\
\hline
\end{tabular}

Médias seguidas da mesma letra maiúscula na coluna não diferem entre si ao nível de $5 \%$ de probabilidades pelo teste de Tukey.

durante a fase de desenvolvimento vegetativo (estádio fenológico de cerca de sete folhas completamente desenvolvidas e $80 \%$ da área foliar total), quando o número potencial de grãos está sendo definido, e o segundo, durante a fase reprodutiva ou a formação dos grãos (período de antese até o grão com camada negra), quando o potencial produtivo é atingido.

No primeiro ano de cultivo (Figuras $2 \mathrm{~B}$ a G), considerando os níveis tecnológicos baixo a alto, os acúmulos máximos de $\mathrm{N}, \mathrm{P}, \mathrm{K}, \mathrm{Ca}, \mathrm{Mg}$ e $\mathrm{S}$, ocorreram entre 84-90, 88-94, 77-79, 86-92, 86-92 e 83-94 DAP, respectivamente. No segundo ano de cultivo (Figuras 3 B a G), os acúmulos máximos dos nutrientes $\mathrm{N}, \mathrm{P}$, $\mathrm{K}, \mathrm{Ca}, \mathrm{Mg}$ e S, ocorreram entre 82-106, 86-105, 7990, 97-129, 88-107 e 87-116 DAP, respectivamente. Destaque para o K, por ter seu acúmulo máximo antecipado em relação aos outros nutrientes, seguido pelo $\mathrm{N}$, o que reforça a recomendação de que a adubação 
de cobertura deve ser realizada até os 20-25 DAE (dias após a emergência) para atender ao período de maior demanda pela planta (Formiga et al., 2012; Borges et al., 2016; Santos et al., 2017).

Ressalta-se também que o $\mathrm{N}$ e K são exigidos de forma mais intensa durante a fase vegetativa, enquanto o P, na fase reprodutiva. Trabalho de Franco (2011) mostrou que as maiores taxas máximas de acúmulo diário (TMAD) de $\mathrm{N}, \mathrm{K}, \mathrm{Ca}, \mathrm{Mg}$ e $\mathrm{S}$ ocorreram entre 42 e 53 DAE para o sorgo forrageiro, e de 31 a 51 DAE para o granífero. No caso do P, a época de maior exigência (TMAD) deu-se pouco mais tarde, aos 62 e 82 DAE, respectivamente, para o sorgo forrageiro e para o granífero.

As quantidades estimadas pelos modelos nos pontos de máximo acúmulo de nutrientes, no primeiro ano de cultivo e considerando os níveis tecnológicos, mostram a elevada demanda em nutrientes pelo sorgo sacarino, com valores variando de 158-243, 1629, 141-416, 46-57, 27-57 e 10-15 kg ha-1 de N, P, K, $\mathrm{Ca}, \mathrm{Mg}$ e $\mathrm{S}$, respectivamente, considerando os dois anos de cultivo (Figuras 2 e 3 B a G).

Ribeiro (2010) em estudo com dois híbridos de sorgo, um forrageiro e outro granífero, cultivados na safrinha e com produtividade máxima média de 14 t ha ${ }^{-1}$ de massa seca total da planta, obteve acúmulo médio de 239, 42, 334, 59, 22 e $15 \mathrm{~kg} \mathrm{ha}^{-1}$ de N, P, K, $\mathrm{Ca}, \mathrm{Mg}$ e $\mathrm{S}$, respectivamente, ou seja, mais próximos dos obtidos neste trabalho; bem como Borges et al. (2016), que com produtividade de $13 \mathrm{t} \mathrm{ha}^{-1}$ de massa seca total de sorgo granífero cultivado na safrinha encontraram extração de 262, 45, 301, 55, 21 e 14 $\mathrm{kg} \mathrm{ha}^{-1}$ de $\mathrm{N}, \mathrm{P}, \mathrm{K}, \mathrm{Ca}, \mathrm{Mg}$ e S, respectivamente. Enquanto Franco (2011), com os mesmos genótipos do trabalho de Ribeiro (2010), mas cultivados na safra, e produtividade máxima média de massa seca total da planta de $17 \mathrm{t} \mathrm{ha}^{-1}$, obteve valores de 303, 55, 331, 93,
34 e $20 \mathrm{~kg} \mathrm{ha}^{-1}$ de N, P, K, Ca, Mg e S, respectivamente, valores esses, à exceção do $\mathrm{K}$ e $\mathrm{Mg}$, maiores que os obtidos neste trabalho.

Considerando que na exploração do sorgo sacarino toda a planta é colhida para a extração do caldo, o que resulta em elevada exportação de nutrientes da área, deve-se atentar para o manejo adequado da adubação da cultura, buscando-se evitar a degradação química do solo com os anos de cultivo. Plantios consorciados, utilização de rotação de culturas, uso de plantas de cobertura e até mesmo colheita que permita a permanência de folhas e panículas na área, além de retorno de resíduos do processamento do colmo, devem ser pensados.

No teste de comparação de médias da extração de nutrientes em relação aos níveis tecnológicos avaliados para o primeiro ano de cultivo e aos 90 DAP (Tabela 1), observa-se que, de maneira geral, houve menor extração dos nutrientes no nível tecnológico muito baixo, seguido do baixo e as maiores extrações dos nutrientes ocorreram nos níveis tecnológicos médio e alto, que não diferiram estatisticamente entre si. Este comportamento era o esperado pelo fato de que havendo maior adubação da cultura há maior produção e, consequentemente, maior demanda e acúmulo de nutrientes. Já no segundo ano de cultivo (Tabela 2), no geral, os níveis tecnológicos muito baixo e baixo apresentaram a mesma quantidade de acúmulo de nutrientes, que foram diferentes dos níveis médio e alto, sendo que estes dois últimos também não diferiram entre si.

Em publicação anterior, envolvendo os mesmos experimentos deste trabalho e avaliação da resposta à adubação NPK da massa de caldo, que é uma das principais variáveis produtivas do sorgo sacarino (Santos et al., 2015), a dose que proporcionou o melhor resultado foi de $100-70-180 \mathrm{~kg} \mathrm{ha}^{-1}$ de $\mathrm{N}_{-} \mathrm{P}_{2} \mathrm{O}_{5}-$ 
$\mathrm{K}_{2} \mathrm{O}$. Portanto, aliado aos dados de acúmulo de massa seca e nutrientes deste trabalho, recomendam-se 160-100-160 kg ha-1 de N- $\mathrm{P}_{2} \mathrm{O}_{5}-\mathrm{K}_{2} \mathrm{O}$, ou seja, doses do nível tecnológico médio, para o sorgo sacarino cultivado em condições edafoclimáticas semelhantes às deste trabalho, buscando otimizar a produção da cultura e a manutenção da fertilidade do solo.

Ressalta-se que para atender à demanda total de nutrientes pela planta haverá contribuição dos nutrientes do solo e de resíduos vegetais de culturas anteriores ao sorgo, devendo-se monitorar constantemente a fertilidade do solo para evitar sua degradação química.

\section{Conclusões}

O acúmulo de massa seca e macronutrientes pelo sorgo sacarino apresentou uma taxa inicial baixa, até cerca de 30 DAP, a partir da qual aumentou consideravelmente, até próximo à maturação do grão, para então se estabilizar e decrescer.

Os valores acumulados de nutrientes pelo sorgo sacarino foram altos, evidenciando a elevada demanda pela planta e alertando para o manejo correto da adubação de forma a não se esgotar o solo com os anos de cultivo, uma vez que toda a planta é colhida da área.

De forma geral, o acúmulo de massa seca foi maior para o nível tecnológico alto, com aplicação de 240-150-240 de $\mathrm{N}, \mathrm{P}_{2} \mathrm{O}_{5}$ e $\mathrm{K}_{2} \mathrm{O}$, respectivamente, e o acúmulo de nutrientes foi igual entre os níveis tecnológicos médio e alto.

Para condições edafoclimáticas semelhantes às deste trabalho, recomenda-se a adubação de 160100-160 N- $\mathrm{P}_{2} \mathrm{O}_{5}-\mathrm{K}_{2} \mathrm{O}$, bem como realizar a cobertura com $\mathrm{N}$ e $\mathrm{K}$ até os 20-25 DAE, para otimizar a produtividade do sorgo sacarino e manter a fertilidade do solo, que deve ser monitorada ao longo dos anos de cultivo.

Dada a grande extração de nutrientes pelo sorgo sacarino, recomendam-se também, além da reposição de nutrientes via adubação, a utilização de plantios consorciados, rotação de culturas, uso de plantas de cobertura e até mesmo a realização da colheita de forma que se permita a permanência de folhas e panículas na área, além de retorno ao solo de resíduos do processamento do colmo.

\section{Referências}

AlBUQUeRQUE, P. E. P.; LANDAU, E. C.; GUIMARÃES, D. P. Aplicativo computacional "Irrigafácil" versão 2.0 implementado via web para o manejo de irrigação de algumas culturas anuais em Minas Gerais. Sete Lagoas: Embrapa Milho e Sorgo, 2013. 25 p. (Embrapa Milho e Sorgo. Documentos, 164).

AMEEN, A.; YANG, X.; CHEN, F.; TANG, C.; DU, F.; FAHAD, S.; XIE, G. H. Biomass yield and nutrient uptake of energy sorghum in response to nitrogen fertilizer rate on marginal land in a semi-arid region. Bioenergy Research, v. 10 , n. 2 , p. $363-376,2017$.

DOI: $10.1007 / \mathrm{s} 12155-016-9804-5$.

AMOUZOU, K. A.; NAAB, J. B.; LAMERS, J. P.; BECKER, M. Productivity and nutrient use efficiency of maize, sorghum, and cotton in the West African Dry Savanna. Journal of Plant Nutrition and Soil Science, v. 181, n. 2, p. 261-274, 2018.

DOI: 10.1002/jpln.201700139.

BORGES, I. D.; FRANCO, A. A. N.; KONDO, M. K.; MARTINS, D. C.; TEIXEIRA, E. C.; MOREIRA, S. G. Acúmulo de macronutrientes na cultura do sorgo granífero na safrinha. Revista Brasileira de Milho e Sorgo, v. 15, n. 2, p. 294-304, 2016.

DOI: 10.18512/1980-6477/rbms.v15n2p294-304. 
BRASIL. Ministério da Agricultura, Pecuária e Abastecimento. A agroenergia no Brasil. Disponível em: $<$ http://www.agricultura.gov.br/assuntos/sustentabilidade/ agroenergia/agroenergia-no-brasil>.Acessoem:13 set.2018.

FERNANDES， G.; BRAGA， T. G.; FISCHER， J.; PARRELLA, R. A.; RESENDE, M. M. de; CARDOSO, V.

L. Evaluation of potential ethanol production and nutrients for four varieties of sweet sorghum during maturation.

Renewable Energy, v. 71, p. 518-524, 2014.

DOI: 10.1016/j.renene.2014.05.033.

FERREIRA, D. F. Sisvar: a computer statistical analysis system. Ciência e Agrotecnologia, v. 35, n. 6, p. 10391042, 2011. DOI: 10.1590/S1413-70542011000600001.

FORMIGA, M. S.; FERREIRA, A. C.; TRAVASSOS, K. D.; BARACUHY, J. G. V.; LIMA, V. L. A.; DANTAS, J. P. A marcha de absorção de nutrientes (NPK) no sorgo granífero sacarino. Revista Educação Agrícola Superior, v. 27, n. 1, p. 3-12, 2012.

FORNASIERE FILHO, D.; FORNASIERE, J. L. Manual da cultura do sorgo. Jaboticabal: Funep, 2009. 202 p.

FRANCO, A. A. N. Marcha de absorção, e acúmulo de nutrientes na cultura do sorgo. 2011. 74 f. Dissertação (Mestrado) - Universidade Estadual de Montes Claros, Montes Claros, 2011.

HAN, L. P.; STEINBERGER, Y.; ZHAO, Y. L.; XIE, G. $\mathrm{H}$. Accumulation and partitioning of nitrogen, phosphorus and potassium in different varieties of sweet sorghum. Field Crops Research, v. 120, n. 2, p. 230-240, 2011. DOI: $10.1016 /$ j.fcr.2010.10.007.

HAO, B.; XUE, Q.; BEAN, B. W.; ROONEY, W. L.; BECKER, J. D. Biomass production, water and nitrogen use efficiency in photoperiod-sensitive sorghum in the Texas High Plains. Biomass and Bioenergy, v. 62, p. 108116, 2014.

DOI: 10.1016/j.biombioe.2014.01.008.
MAW, M. J.; HOUX III, J. H.; FRITSCHI, F. B. Sweet sorghum ethanol yield component response to nitrogen fertilization. Industrial Crops and Products, v. 84, p. 4349, 2016. DOI: 10.1016/j.indcrop.2016.01.038.

REGASSA, T.; WORTMANN, C. S. Sweet sorghum as a energy crop: literature review. BiomassBioenerg, v. 64, p. 348-355, 2014. DOI: 10.1016/j.biombioe.2014.03.052.

RIBEIRO, A. S. Marcha de absorção e acúmulo de nutrientes no sorgo cultivado no norte de Minas Gerais. 2010. 45 f. Monografia (Graduação em Engenharia Agronômica) - Universidade Estadual de Montes Claros, Janaúba, 2010.

SANTOS, F. C.; RESENDE, A. V.; ALBUQUERQUE FILHO, M. R.; MAY, A.; CRUZ, S. C. B.; GRAVINA, G. de A.; PARRELLA, R. A. C. Resposta do sorgo sacarino à adubação NPK em Latossolo de cerrado da região central de Minas Gerais. Sete Lagoas: Embrapa Milho e Sorgo, 2015. 35 p. (Embrapa Milho e Sorgo. Boletim de Pesquisa e Desenvolvimento, 130).

SANTOS, F. C.; RESENDE, A. V.; SIMEONE, M. L. F.; PASSOS, A. M. A.; ALBUQUERQUE FILHO, M. R.; PARrElla, R. A. C.; JULIO, G. M. F. Demanda nutricional do sorgo sacarino para a recomendação de adubação. Sete Lagoas: Embrapa Milho e Sorgo, 2017. 6 p. (Embrapa Milho e Sorgo. Circular Técnica, 235).

SOARES, E. R.; COUTINHO, E. L. M.; RAMOS, S. B.; SILVA, M. S.; BARBOSA, J. C. Accumulation of dry matter and macronutrients in sweet sorghum cultivars. Semina: Ciências Agrárias, v. 35, n. 6, p. 3015-3030, 2014.

DOI: $10.5433 / 1679-0359.2014 v 35 n 6 p 3015$.

WORTMANN, C. S.; LISKA, A.; FERGUSON, R. B.; LYON, D. J.; KLEIN, R. N. Dryland performance of sweet sorghum and grain crops for biofuel in Nebraska. Agronomy Journal, v. 102, n. 1, p. 319-326, 2010. DOI: 10.2134/agronj2009.0271. 